\title{
Hydrothermal Synthesis and Characterization of Ni-Al Montmorillonite-Like Phyllosilicates
}

\section{Marc X. Reinholdt ${ }^{1, *}$, Jocelyne Brendlé ${ }^{2}$, Marie-Hélène Tuilier ${ }^{3}$, Serge Kaliaguine ${ }^{4}$ and Emmanuelle Ambroise ${ }^{2}$}

1 Université de Poitiers, CNRS UMR 7285 IC2MP, ENSIP-Bât. B1, 1 Rue Marcel Doré, F-86022 Poitiers cedex, France

2 Université de Haute Alsace (UHA), CNRS, Equipe Matériaux à Porosité Contrôlée (MPC), Institut de Science des Matériaux de Mulhouse (IS2M), LRC 7228, F-68093 Mulhouse, France; E-Mails: jocelyne.brendle@uha.fr (J.B.); emmanuelle.ambroise@uha.fr (E.A.)

3 Université de Haute Alsace (UHA), Laboratoire Physique et Mécanique Textile (LPMT), EA 4365 (conventionnée au CNRS), F-68093 Mulhouse, France; E-Mail: marie-helene.tuilier@uha.fr

4 Département de Génie Chimique, Université Laval, 1065 ave. de la Médecine, Québec, QC G1V 0A6, Canada; E-Mail: serge.kaliaguine@gch.ulaval.ca

* Author to whom correspondence should be addressed; E-Mail: marc.reinholdt@univ-poitiers.fr; Tel.: +33-5-49-45-40-48.

Received: 4 December 2012; in revised form: 3 January 2013 / Accepted: 14 January 2013 / Published: 21 January 2013

Abstract: This work describes the first hydrothermal synthesis in fluoride medium of Ni-Al montmorillonite-like phyllosilicates, in which the only metallic elements in the octahedral sheet are Ni and Al. X-ray diffraction, chemical analysis, thermogravimetric and differential thermal analysis, scanning electron microscopy and transmission electron microscopy confirm that the synthesized samples are montmorillonite-like phyllosilicates having the expected chemical composition. The specific surface areas of the samples are relatively large ( $\left.>100 \mathrm{~m}^{2} \mathrm{~g}^{-1}\right)$ compared to naturally occurring montmorillonites. ${ }^{29} \mathrm{Si}$ and ${ }^{27} \mathrm{Al}$ nuclear magnetic resonance (NMR) indicate substitutions of $\mathrm{Al}$ for $\mathrm{Si}$ in the tetrahedral sheet. ${ }^{19} \mathrm{~F}$ NMR and Ni $K$-edge extended X-ray absorption fine structure (EXAFS) local probes highlight a clustering of the metal elements and of the vacancies in the octahedral sheet of the samples. These Ni-Al phyllosilicates exhibit a higher local order than in previously synthesized $\mathrm{Zn}-\mathrm{Al}$ phyllosilicates. Unlike natural montmorillonites, where the distribution of transition metal cations ensures a charge equilibrium allowing a stability of the framework, synthetic montmorillonites entail clustering and instability of 
the lattice when the content of divalent element in the octahedral sheet exceeds $c a .20 \%$. Synthesis of Ni-Al montmorillonite-like phyllosilicates, was successfully achieved for the first time. These new synthetic materials may find potential applications as catalysts or as materials with magnetic, optical or staining properties.

Keywords: clay; montmorillonite; synthesis; fluoride medium; solid-state NMR; EXAFS

\section{Introduction}

Clay minerals have been widely used by human societies since the early days of mankind [1-3]. Modern uses of clay minerals cover a large variety of domains like building materials, ceramics, absorbents, ion exchangers, cosmetic and pharmaceutical products, oil drilling, foundry and paper industries, wastes confinement (including nuclear wastes), pollutants removal, catalysis and polymer nanocomposite reinforcement [4-9]. Clay minerals consist of a variety of phyllosilicates, commonly observed on Earth, which can be divided into several groups depending on the layer type (1:1, 2:1 or $2: 1: 1)$, charge per formula unit and nature of structural elements and interlayer species $[3,10]$. These groups are: kaolin-serpentine (1:1 phyllosilicate), pyrophyllite-talc, smectite, vermiculite, mica (all of them being 2:1 phyllosilicates) and chlorite (2:1:1 phyllosilicate). Among these various groups, smectites are largely used because of their high adsorption (so important that they are designated as swelling clays), acidic and cation exchange properties [3,10]. Within the smectite family, montmorillonite clay is the most common and used one, mainly because of the existence of large deposits, yielding a very low cost raw material [11,12]. The ideal 2:1 layer structure of montmorillonite is constituted by a sheet of $\mathrm{AlM}(\mathrm{OH})_{2} \mathrm{O}_{4}$ octahedra $(\mathrm{M}$ being a divalent element, mostly $\mathrm{Mg}$ ) sandwiched between two sheets of $\mathrm{SiO}_{4}$ tetrahedra [11]. The intrinsic isomorphic substitution of Al by divalent elements in the octahedral sheet and the frequent substitution of Si by Al in the tetrahedral sheets are at the origin of the structure's negative charge. This charge is compensated by cations located in the gallery between the clay sheets. Montmorillonite contains two $\mathrm{Al}(\mathrm{M})$ elements in the centre of two out of three octahedra, the third one being vacant, making it a member of the dioctahedral smectite subgroup. Tetrahedral substitutions, heterogeneous elemental compositions, varying particle size, structural clustering and important amounts of impurities, limit the use of natural clay minerals for particular applications such as catalysis [12].

Thus, it becomes interesting to explore the synthesis of some attractive clay minerals, like montmorillonite, to develop pure products with well-known compositions, morphologies, particle sizes and structural element arrangements for specific applications. In this context, synthesis of montmorillonite was specifically explored with the aim of obtaining reference clay-like compounds [3,13-16]. The hydrothermal synthesis route remains the preferred method used by scientists working either in materials or geological sciences, because it is a versatile and easy to use method, which allows the attainment of well crystallized materials. Conditions of synthesis of pure montmorillonite remains relatively soft, with temperatures in the range $100-475{ }^{\circ} \mathrm{C}$, pressures below $10 \mathrm{MPa}$ (autogenously generated) and up to $120 \mathrm{MPa}$, and mildly acidic to strongly basic $\mathrm{pH}$ values (ca. 5 to 14). While the synthesis of pure $\mathrm{Zn}-\mathrm{Al}$ or $\mathrm{Mg}$-Fe montmorillonite-like minerals, containing 
only $\mathrm{Zn}$ and $\mathrm{Al}$ or $\mathrm{Mg}$ and $\mathrm{Fe}$ in the octahedral sheet, has been achieved [17,18], the synthesis of $\mathrm{Mg}$-Al montmorillonite-like phases, containing only $\mathrm{Mg}$ and $\mathrm{Al}$ in the octahedral sheet, was only accomplished recently [13-16]. A first breakthrough was realized by using the fluoride route synthesis method $[13,14]$, which allows syntheses over a large $\mathrm{pH}$ range from acidic $(\mathrm{pH} \approx 2-3)$ to strongly basic $(\mathrm{pH} \approx 13)$. Additionally, fluoride $\left(\mathrm{F}^{-}\right)$acts as a mineralizing agent together or with replacement of hydroxide $\left(\mathrm{OH}^{-}\right)$. Another great advancement was performed more recently by a two-step method involving a first part in which an amorphous gel is prepared by basification, from $\mathrm{pH} \approx 2$ to 6 using $\mathrm{NH}_{4} \mathrm{OH}$, of the chemical reagents mixture inducing the precipitation of the gel $[15,16]$. The second step of this method consists of hydrothermally treating the resulting amorphous gel by controlling both temperature and pressure of the synthesis to crystallize the montmorillonite-like mineral. Since this method of synthesis uses an organosilicon compound as the silicon source, i.e., tetraethylorthosilicate, it does not mimick well the natural crystallization processes, however it enables well crystallized low-charge clay-minerals to be obtained with a controlled chemical composition.

On another aspect, natural clay minerals are known to be efficient acid catalysts due to their Brønsted and Lewis acidities [12,19]. These naturally occurring minerals are non-corrosive, low-cost materials, can be reused and thus the amount of wastes is limited. However, several structural and chemical heterogeneities and the presence of impurities restrict the use of these natural clays for some catalytic applications. As a consequence, the design of synthetic clay minerals becomes attractive with the aim of tailoring their chemical composition, cation exchange capacity, acidity or swelling properties. In recent years interest was particularly directed toward manipulating the nature and the amount of heteroatoms in the clay layers through isomorphous substitutions. Among these substituted new catalysts, Ni-phyllosilicates have been recently evaluated for the epoxidation of ( $\mathrm{Z}$ )-cyclooctene and the oxidation of cyclohexanone in the presence of benzonitrile (Ni-saponite) [20], and for the $\mathrm{CO}_{2}$ reforming of methane (Ni-lizardite and Ni-talc) [21,22].

In this context, the first goal of our study was to demonstrate that the synthesis of $\mathrm{Ni}-\mathrm{Al}$ montmorillonite-like phyllosilicates, containing only $\mathrm{Ni}$ and $\mathrm{Al}$ in the octahedral sheet, is possible. But the second essential objective was to thoroughly characterize the structures and evaluate the textural properties of the new synthetic minerals. Syntheses were performed following the fluoride route by adapting the method used to prepare $\mathrm{Mg}$-Al or $\mathrm{Zn}$-Al montmorillonite-like phyllosilicates [13,14]. Synthesized Ni-Al containing samples were characterized using X-ray diffraction (XRD), chemical analysis, scanning electron microscopy (SEM), transmission electron microscopy (TEM), thermogravimetric and differential thermal analysis (TGA-DTA), nitrogen adsorption-desorption experiments using the Brunauer Emmett and Teller method (BET), solid state magic angle spinning nuclear magnetic resonance (MAS-NMR) for the ${ }^{29} \mathrm{Si},{ }^{27} \mathrm{Al}$ and ${ }^{19} \mathrm{~F}$ nuclei and Ni $K$-edge extended $\mathrm{X}$-ray absorption fine structure (Ni K-EXAFS) spectroscopies. This is the first report of the synthesis of Ni-Al montmorillonite-like clay minerals, containing only $\mathrm{Ni}$ and $\mathrm{Al}$ in the octahedral layer.

\section{Results and Discussion}

The synthetic compounds prepared in this work are fine green powders, the color of which is more intense as the Ni content increases. 


\subsection{X-Ray Diffraction}

XRD patterns of samples $\mathrm{Ni01}$ and Ni02 exhibit $h k$ bands and $00 l$ reflections characteristic of phyllosilicates (Figure 1a). More specifically, the bands appearing at $c a .20,35,55$ and $62^{\circ} 2 \theta$, can be indexed as the $(02,11),(13,20),(15,24,31)$ and $(06,33)$ bands of a smectite mineral $[11,12,23-25]$. The number of octahedra occupied by metal elements defines the di- or trioctahedral character of the clay, i.e., one or no vacancy out of three octahedra respectively. The position of the (06) band is related to this character, with associated $d_{060}$ periodicity values of 1.49 and $1.52 \AA$ respectively. Figure $1 \mathrm{~b}$ displays the (060) bands of samples Ni01 and Ni02. The $d_{060}$ periodicity of sample Ni01 is dominated by a peak centered at $c a$. $1.49 \AA$ making it a solely dioctahedral mineral. Sample Ni02 exhibits two components, a main one at $1.49 \AA$ and a secondary one at $1.51 \AA$, the latter demonstrating a partial trioctahedral character of the layers. The position of the (001) peak (Figure 1a), observed at $c a$. 12.7 and $13.2 \AA$ for Ni01 and Ni02 samples respectively, gives the value of the interlayer distance and is typical of the smectite mineral family. The much broader (001) peak observed for Ni01 sample is characteristic of a reduced size of the coherent scattering domains perpendicular to the layer plane. To confirm these swelling properties, sample Ni02 was further subjected to hexadecyltrimethylammonium (HDTMA) intercalation. The intercalated hybrid-mineral shows a $d_{001}$ spacing at $c a .16 .8 \AA$ (Figure 1c), which corresponds to values usually observed for a laterally intercalated monolayer of HDTMA in montmorillonite minerals [26-29].

Figure 1. X-ray diffraction (XRD) patterns of synthetic Ni-Al phyllosilicates, samples Ni01 and Ni02: (a) whole diffractograms recorded at $P / P_{0}=0.80$; (b) position of the (060) peak and (c) pattern of sample Ni02 $(x=0.2)$ exchanged with hexadecyltriethylammonium bromide.

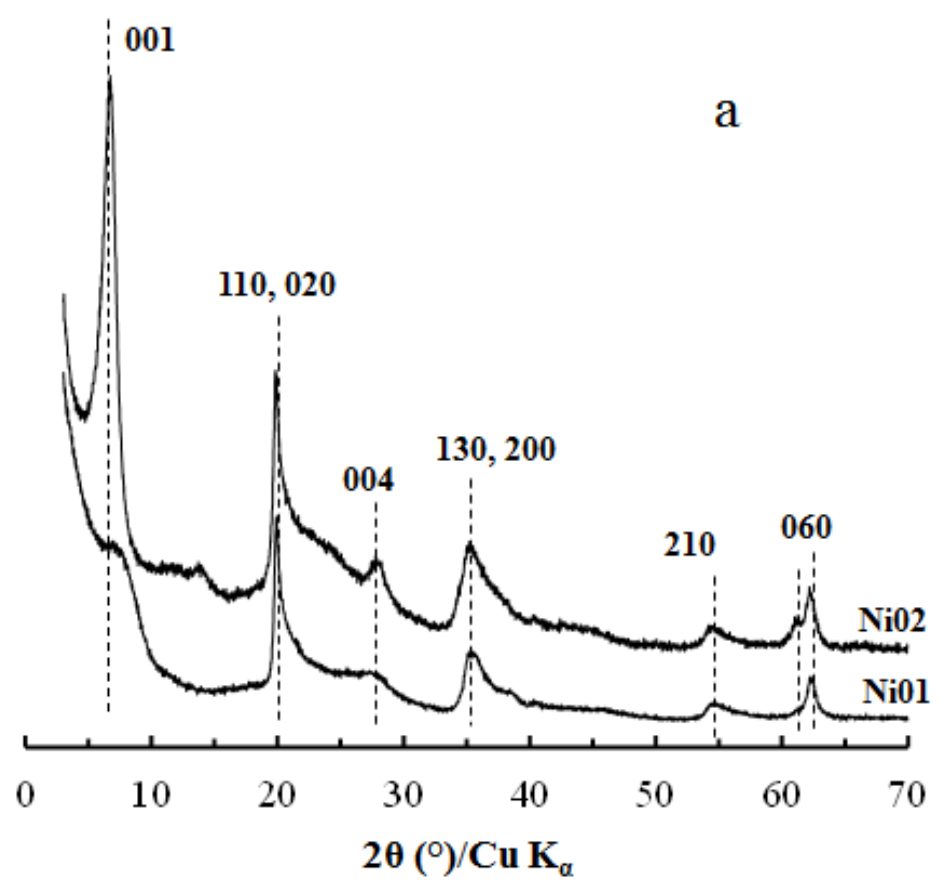


Figure 1. Cont.
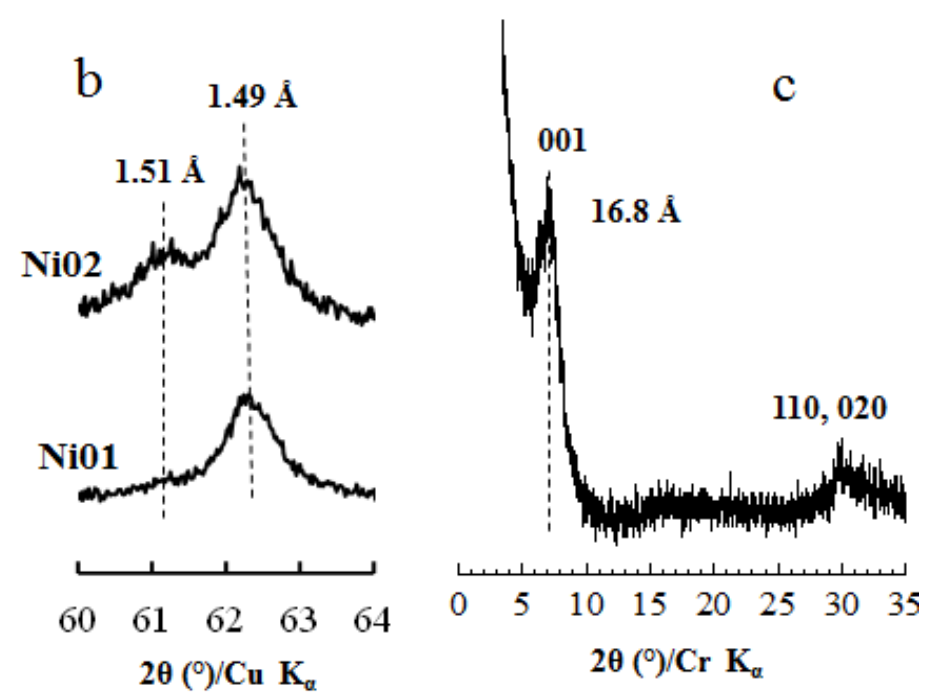

\subsection{Chemical Analysis}

The two samples were analyzed for their chemical content (wt.\%): Ni01 (Si: 27.40; Al: 9.00; Ni: 3.20; Na: 0.40; F: 0.47) and Ni02 (Si: 25.50; Al: 8.20; Ni: 7.50; Na: 0.40; F: 0.35). The amounts of $\mathrm{Si}, \mathrm{Al}, \mathrm{Na}$ and $\mathrm{F}$ are relatively similar in both samples, but the amount of $\mathrm{Ni}$ is more than doubled in sample Ni02 compared to sample Ni01, as expected from the chemical composition ot the initial reacting mixtures. Additionally, it seems that the Al content slightly decreases as the Ni content increases, as one would expect with a partial substitution of Al by $\mathrm{Ni}$ in the octahedral layer. This higher Ni content in the Ni02 sample corroborates the more intense color observed for that sample with respect to sample $\mathrm{NiO} 1$.

\subsection{Scanning and Transmission Electron Microscopy}

Typical SEM and TEM pictures of samples Ni01 and Ni02 are shown on Figure 2. The synthetic inorganic compounds exhibit the well-known sand rose or cornflake morphology (Figure 2a), which is typically observed for natural clay minerals [30-32], especially for swelling phyllosilicates of the smectite family.

Figure 2. Representative (a) scanning electron microscopy (SEM) and (b) transmission electron microscopy (TEM) micrographs of our synthetic Ni-Al phyllosilicates.
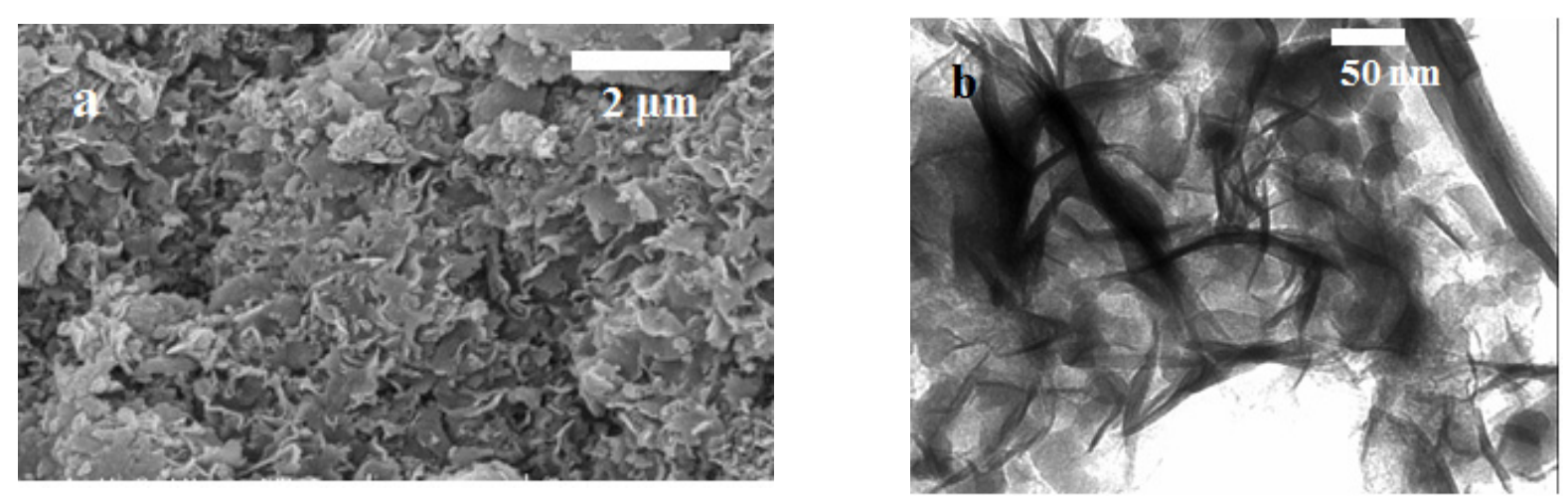
TEM micrographs of our samples (Figure 2b) show that the synthetic minerals seem to possess a layered structure characteristic of smectite clay minerals, either natural [27,33] or synthetic [15].

\subsection{Thermal Analyses}

The thermogravimetric and thermal analysis curves of samples Ni01 and Ni02 are displayed in Figure 3.

Figure 3. Thermogravimetric and differential thermal analysis (TGA-DTA) patterns of samples Ni01 and Ni02.
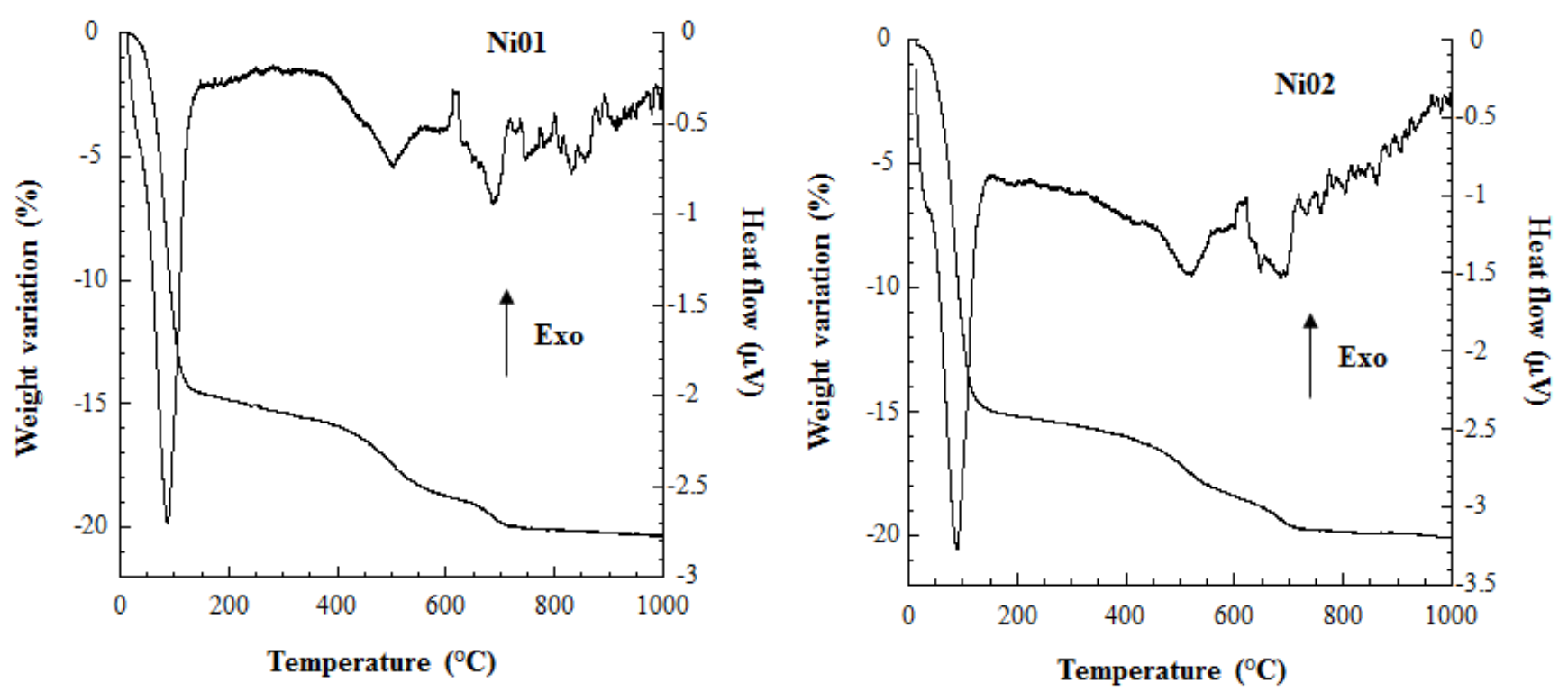

The curves are very similar for both samples and exhibit a first main weight variation below $110{ }^{\circ} \mathrm{C}$ of $c a .14 .4$ and 15.4 wt.\% for samples Ni01 and Ni02, respectively. This weight loss is associated with a large endothermic peak on the heat flow vs. temperature curve and they are both associated with clay mineral interlayer dehydration [34-37]. Both samples experience also two weight losses at ca. 500 and $680{ }^{\circ} \mathrm{C}$, combined to endothermic peaks, which are of the order of 3.0-3.3 and 1.4-1.5 wt.\%, respectively. These features are attributed to the dehydroxylation of the clay layer. The dehydroxylation appearing at the highest temperature is characteristic of montmorillonite clay minerals [34-36] and was also observed for a synthetic montmorillonite-like mineral, which was hydrothermally synthesized at higher pressure and temperature than in our case [15]. The dehydroxylation appearing at lower temperatures has already been observed in some natural montmorillonites [34,37], and is also a peculiar feature of our synthetic Mg-Al or $\mathrm{Zn}-\mathrm{Al}$ montmorillonite-like minerals, containing only $\mathrm{Mg}$ and $\mathrm{Al}$ or $\mathrm{Zn}$ and $\mathrm{Al}$ in the octahedral layer $[13,14]$. These features correspond to two types of structural hydroxyls, assigned to trans- and cis-vacant sites, i.e., the two occupied octahedra are positioned perpendicularly or parallel to the line formed by the hydroxyls in the structural plane, and associated with the lower and higher temperature dehydroxylation peaks respectively $[35,36]$. Thus, the presence of cis- and trans-vacant sites may arise from structurally different layers, i.e., cis or trans 2:1 layers [35,36], or from a clustering of either the dioctahedral elements or the hydroxyl/fluorine groups or both during the synthesis process. Such 
possible clustering was observed in montmorillonite-like samples synthesized at low temperature and pressure and in slightly acidic and fluoric medium (see [13,14] and vide infra). As mentioned above montmorillonite-like minerals synthesized at higher temperature and pressure seem to contain only cis-vacant sites in their structure making them more homogeneous minerals. As a consequence of the previous discussion, the dehydroxylation observed at $c a .450-500{ }^{\circ} \mathrm{C}$ might be considered as a fingerprint of montmorillonite-like minerals synthesized in conditions similar as those presented here and in our previous studies $[13,14]$. Additionally, it is noteworthy that dehydroxylations of the Ni-Al montmorillonite-like minerals appear at temperatures slightly higher ( $c$. $20^{\circ}$ to $40^{\circ}$ ) than those observed for the $\mathrm{Mg}-\mathrm{Al}$ or $\mathrm{Zn}-\mathrm{Al}$ synthetic montmorillonites [13,14], making the former slightly more thermally stable.

\section{5. $\mathrm{N}_{2}$ Adsorption}

The specific surface areas (SSA) of the samples are 115 and $134 \mathrm{~m}^{2} \mathrm{~g}^{-1}$ for Ni01 and Ni02, respectively. These values are higher than those usually observed for natural montmorillonites [38-41], though they are not unexpected since a synthetic $\mathrm{Mg}$-Al montmorillonite showed a SSA of $c a$. $128 \mathrm{~m}^{2} \mathrm{~g}^{-1}$ [42]. However, this synthetic montmorillonite-like clay mineral was recently studied for its dissolution kinetics [43], and a purified sample exhibited a $104 \mathrm{~m}^{2} \mathrm{~g}^{-1} \mathrm{SSA}$. Thus the high SSA values observed for the $\mathrm{Ni}$-Al montmorillonite-like synthetic minerals are probably due to the presence of an additional silica amorphous phase detected by ${ }^{29} \mathrm{Si}$ NMR (vide infra). This assumption is sustained by the fact that the SSA value increases from sample Ni01 to Ni02, as the amount of silica seems to increase (vide infra).

\subsection{Solid State Nuclear Magnetic Resonance}

In order to see whether there is also $\mathrm{Al}$ for Si substituted in the tetrahedral sheet, ${ }^{27} \mathrm{Al}$ and ${ }^{29} \mathrm{Si}$ solid state MAS-NMR experiments were carried out.

The ${ }^{29}$ Si MAS-NMR spectra of samples Ni01 and Ni02 exhibit a main peak at ca. -93 ppm, a shoulder on its left side at $c a$. $-88 \mathrm{ppm}$ and a very broad, though relatively important, peak at ca. $-108 \mathrm{ppm}$ (Figure 4). These features can be readily assigned to the $\mathrm{Si}(0 \mathrm{Al})$ environment [44-47], i.e., Si surrounded by three $\mathrm{Si}$ in the tetrahedral sheet, the $\mathrm{Si}(1 \mathrm{Al})$ environment [44-47], i.e., $\mathrm{Si}$ surrounded by two Si and one Al in the tetrahedral sheet, and to amorphous silica [14], respectively. The $\mathrm{Si}(1 \mathrm{Al})$ environment occurrence is characteristic of $\mathrm{Al}$ for Si substitutions in the tetrahedral sheet. A slight shielding of the $\mathrm{Si}(0 \mathrm{Al})$ environment chemical shift, $c a$. $0.2 \mathrm{ppm}$, is observed between samples Ni01 and Ni02. This slide of the chemical shift to higher field values may be related to the partial trioctahedral character of Ni02 sample [46,47], in agreement with XRD observations (vide supra). The signal to noise ratio of the spectra is relatively low and probably due to the presence of amorphous silica. The presence of amorphous silica was also observed in the previously synthesized $\mathrm{Mg}-\mathrm{Al}$ or $\mathrm{Zn}-\mathrm{Al}$ montmorillonite-like phyllosilicates, but not to such an extent [14]. This demonstrates clearly that the conditions of synthesis of montmorillonite-like clay minerals, consequently their occurrence in nature, might be strongly affected by the type of metal cations present in the medium. Because of the low quality of the spectra, it was not possible to properly simulate them and gather more information. 
Figure 4. ${ }^{29} \mathrm{Si}$ nuclear magnetic resonance (MAS-NMR) spectra of samples Ni01 and Ni02.

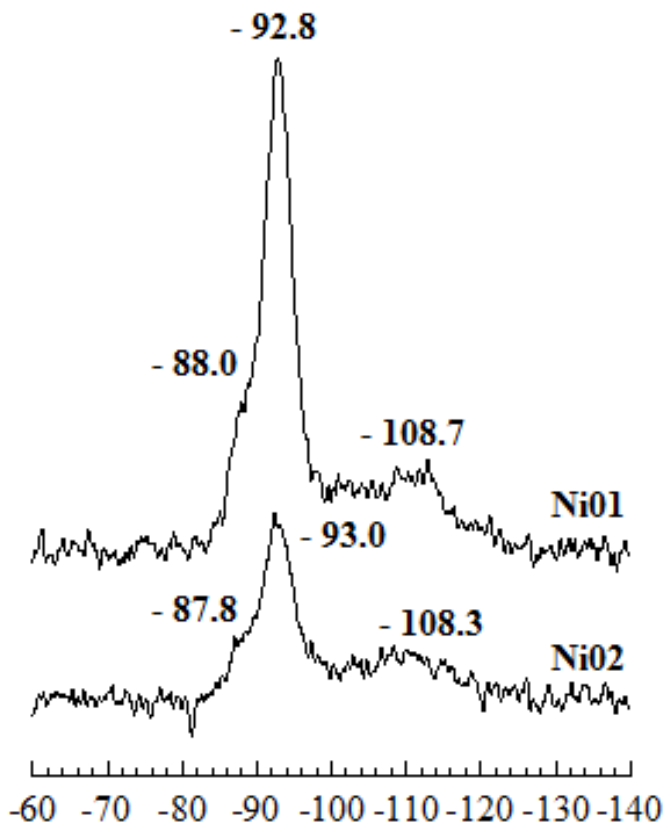

\section{$\delta(\mathbf{p p m} / \mathbf{T M S})$}

${ }^{27}$ Al MAS-NMR spectra of samples Ni01 and Ni02 (Figure 5) present a main asymmetric peak at ca. 3 ppm characteristic of the octahedral aluminum environment $\left(\mathrm{Al}_{\mathrm{VI}}\right)[44,46,48,49]$. The resonances observed in the range 50-70 $\mathrm{ppm}$ are assigned to the tetrahedral aluminum environment $\left(\mathrm{Al}_{\mathrm{IV}}\right)[44,46,48,49]$. The presence of these resonances confirms that there are both octahedral and tetrahedral substitutions in these synthetic montmorillonite-like Ni-Al phyllolicates. The Ni01 spectrum shows only one asymmetric peak at $c a .68 \mathrm{ppm}$, while the Ni02 spectrum shows two peaks, an asymmetric one at $c a .68 \mathrm{ppm}$ and a smaller one at $c a .55 \mathrm{ppm}$. In the latter case, the existence of two different $\mathrm{Al}_{\mathrm{IV}}$ resonances might be correlated to the clustering of the metallic elements in the octahedral sheet (vide infra).

Since fluorine atoms may have two or three octahedrally coordinated elements (Al, Ni) in their environment, fluorine was used as a local probe for the determination of the various tri-hexagonal sequences present in the octahedral sheet. Huve has shown that depending on the dioctahedral or the trioctahedral character a relationship can be established between the average of the electronegativity of the octahedral sheet elements $\left(e_{\square}\right)$ and the theoretical ${ }^{19} \mathrm{~F}$ chemical shift $\left(\delta_{19 \mathrm{~F}}\right)$ [50]. In the case of dioctahedral clays the following relation can be used: $\delta_{19 \mathrm{~F}}=117 e_{\square}-247$, whereas for trioctahedral clays it is the following one: $\delta_{19 F}=50 e_{\square}-238$. Assuming the presence of Al-Al- $\square$, Al-Ni- $\square$ or Ni-Ni-Ni tri-hexagonal sites, their theoretical chemical shifts should be $-132,-121$ and $-150 \mathrm{ppm}$, respectively. However, the presence of a paramagnetic center, e.g., Ni, can cause (sometimes large) chemical shift changes, known as paramagnetic shifts, and in this case the experimental chemical shift can greatly differ from the theoretical one. ${ }^{19} \mathrm{~F}$ MAS-NMR spectra of samples Ni01 and Ni02 (Figure 6) present a main resonance at $c a$. $-132 \mathrm{ppm}$, which is assigned to the Al-Al- $\square$ environment $[13,14,51]$, one fluorine surrounded by two aluminum and one vacancy in the three neighboring octahedra (Figure 7). Both spectra exhibit a peak at $c a .-122 \mathrm{ppm}$, which may be assigned to an Al-Ni- $\square$ environment [50]. Finally, both spectra show a third resonance at $c a .-139$ ppm, which 
might be assigned to the Ni-Ni-Ni environment [50], for which a chemical shift of about 10 ppm is observed with respect to the theoretical value. The chemical shift change observed in the case of the $\mathrm{Ni}-\mathrm{Ni}-\mathrm{Ni}$ environment and not for the Al-Ni- $\square$ environment might be explained by the much stronger local concentration of Ni. The Ni-Ni-Ni environment is thus observed in both samples and especially in sample Ni01, which is a purely octahedral mineral according to XRD (vide supra). Since no such trioctahedral clusters are expected in sample Ni01, this is evidence of the clustering of $\mathrm{Ni}$, but also of the vacancies and possibly of the fluorine in the octahedral sheet.

These NMR observations of the existence of a clustering of the metal elements in the octahedral layer support the results deduced from Ni $K$-edge EXAFS (vide infra).

Figure 5. ${ }^{27} \mathrm{~A} 1 \mathrm{MAS}-\mathrm{NMR}$ spectra of samples Ni01 and Ni02.

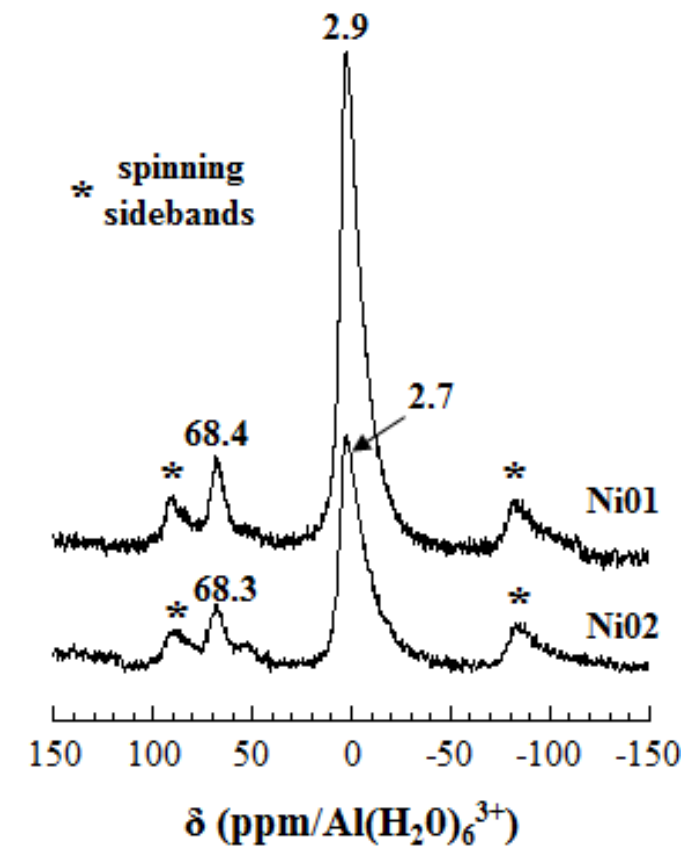

Figure 6. ${ }^{19} \mathrm{~F}$ MAS-NMR spectra of sample Ni01 and Ni02.

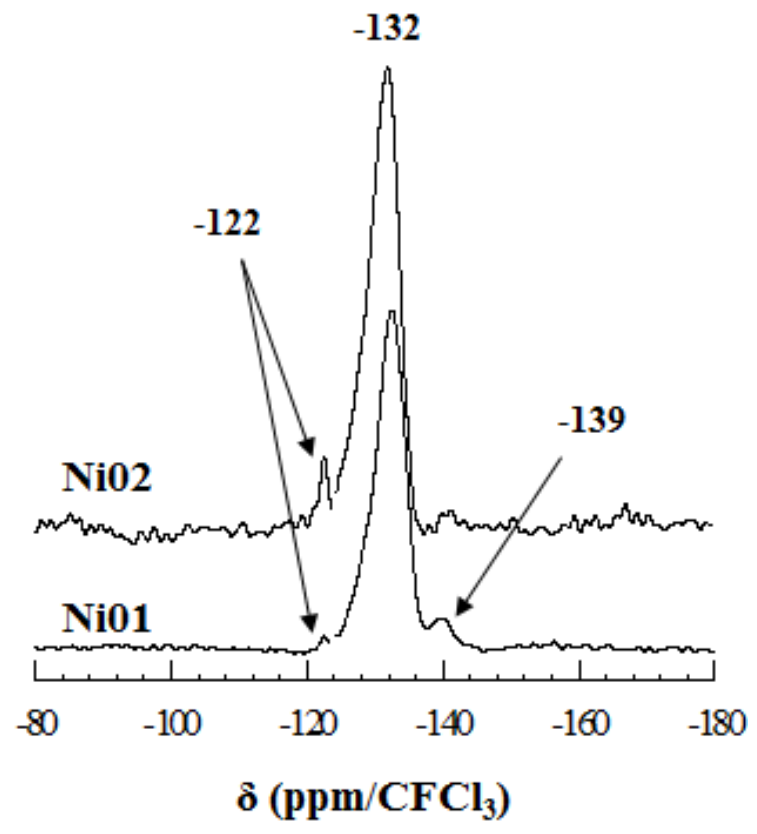


Figure 7. In plane structure of the octahedral layer.

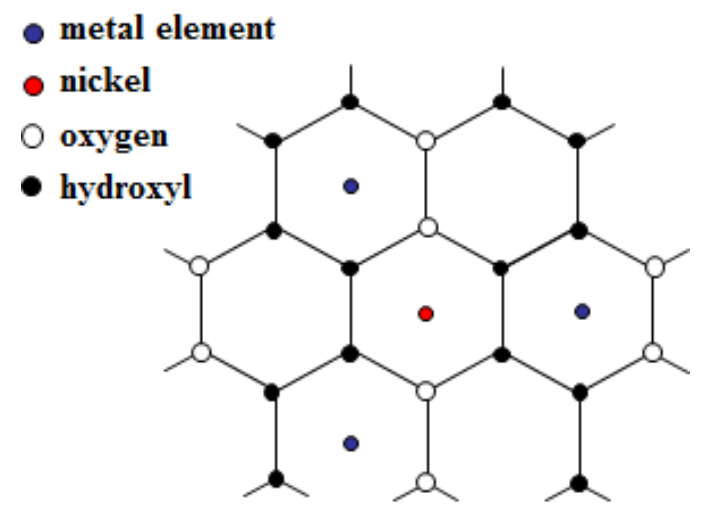

\subsection{Ni K-Edge Extended X-Ray Absorption Fine Structure}

Samples Ni01 and Ni02 were analyzed on synchrotron facilities to perform EXAFS measurements at the Ni $K$-edge $(8333 \mathrm{eV})$. The experimental $\chi(\mathrm{k})$ spectra of the two samples and their Fourier transformed (FT) magnitudes are displayed in Figure 8a and 8b, respectively. One can easily observe that both sets of data are very similar, showing that the local environment of $\mathrm{Ni}$ atoms is much the same in both samples. The first and second main peaks on the FT magnitudes are assigned to the nearest neighbor (NN) and next nearest neighbor (NNN) shell contributions, respectively (Figure 8b). There are only tiny differences in the data sets and they are actually best noticed for values beyond $3 \AA$ in the R space. As a consequence, differences between samples will only affect, slightly, the NNN shell contributions. The Ni NN shell contribution consists of oxygen atoms, and the NNN shell contains the $\mathrm{Ni}$ and $\mathrm{Al}$ atoms present in the surrounding octahedra and $\mathrm{Si}$ and $\mathrm{Al}$ nuclei present in the closest tetrahedra. While comparing this set of $\mathrm{Ni} K$-edge data to those obtained at the $\mathrm{Zn}$ and $\mathrm{Mg}$ $K$-edges for montmorillonite-like phyllosilicates [13], one can easily observe that the NNN shell contributions of the FT spectra are more affected by the metallic elements content in the case of the $\mathrm{Zn}-\mathrm{Al}$ or $\mathrm{Mg}-\mathrm{Al}$ samples than in the case of the Ni-Al ones.

Figure 8. (a) Ni $K$-edge extended X-ray absorption fine structure (Ni $K$-EXAFS) spectra and (b) Fourier transformed (FT) magnitudes of the $\mathrm{k}^{2}$-weighted EXAFS data of the Ni01 and Ni02 samples.
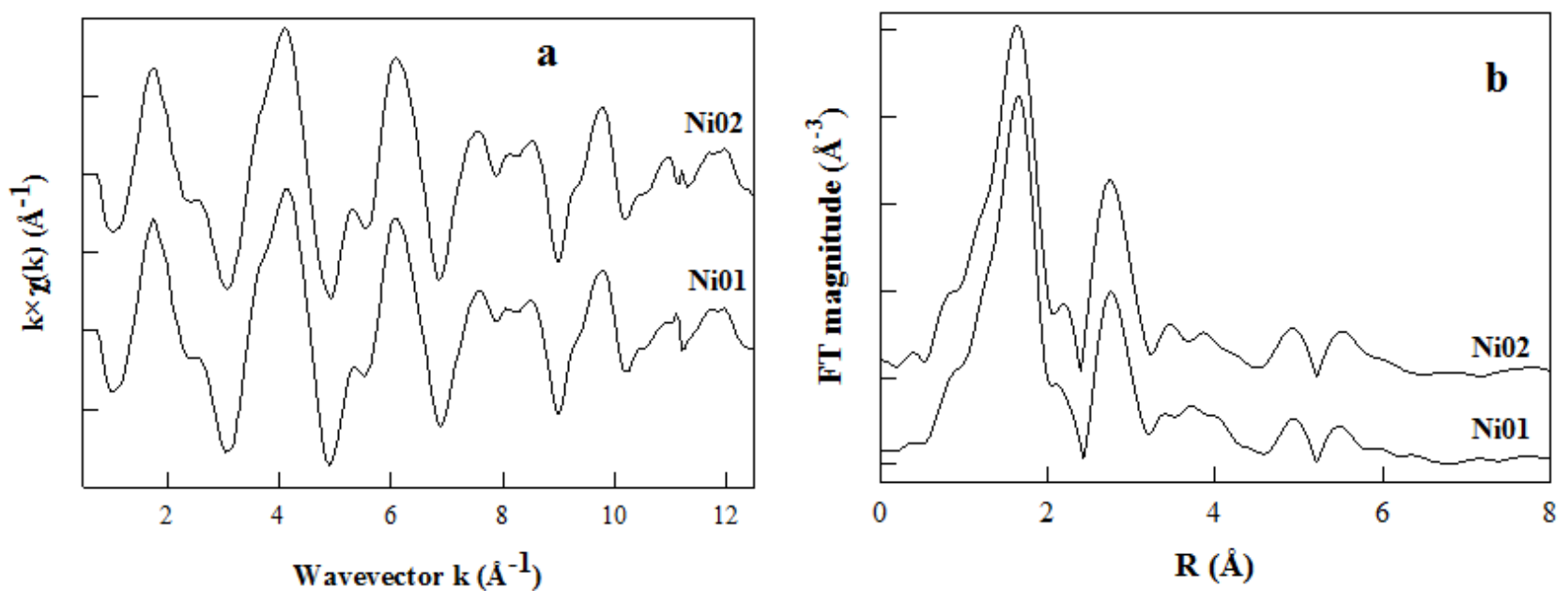
The best simulations of the Fourier-filtered (FF) contribution of the NN peak for both Ni-Al samples are represented in Figure 9 and the structural parameters derived from these simulations are reported in Table 1. Ni nuclei have the same octahedral environment (six oxygen neighbors) in both Ni01 and Ni02 samples, as was observed previously for the synthetic montmorillonite-like phyllosilicates containing $\mathrm{Zn}$ and $\mathrm{Al}$ or $\mathrm{Mg}$ and $\mathrm{Al}$ (see samples $\mathrm{Zn01}, \mathrm{Zn02}, \mathrm{Mg} 01$ and $\mathrm{Mg} 02$ in Table 1) [13]. Additionally, one may see that the $\mathrm{M}-\mathrm{O}$ distance is relatively close in the samples containing the same metallic element (M), meaning that it is independent of the amount contained in the sample. Though the M-O distance increases with the diameter of the $\mathrm{M}$ element, especially in the case of the two largest nuclei, $\mathrm{Mg}$ and $\mathrm{Zn}$ (Table 1; atomic radii: $\mathrm{Ni}^{2+}-0.69 \AA, \mathrm{Zn}^{2+}-0.74 \AA$, $\mathrm{Mg}^{2+}-0.72 \AA$ ). When comparing these $\mathrm{M}-\mathrm{O}$ distances to the Al-O distance determined in $\mathrm{Zn}-\mathrm{Al}$ or Mg-Al montmorillonites (ca. $1.93 \AA$ ) [52], or to the theoretical Mg-O and Al-O distances (2.15 and $1.91 \AA$, respectively) described for an ideal montmorillonite structure (Figure 1 in this reference) [53], one can deduce that the octahedron size increase induces enhanced distortions of the layer structure.

Figure 9. Best fits performed on the Fourier-filtered NN shell contribution of samples Ni01 and Ni02 using the parameters reported in Table 1.
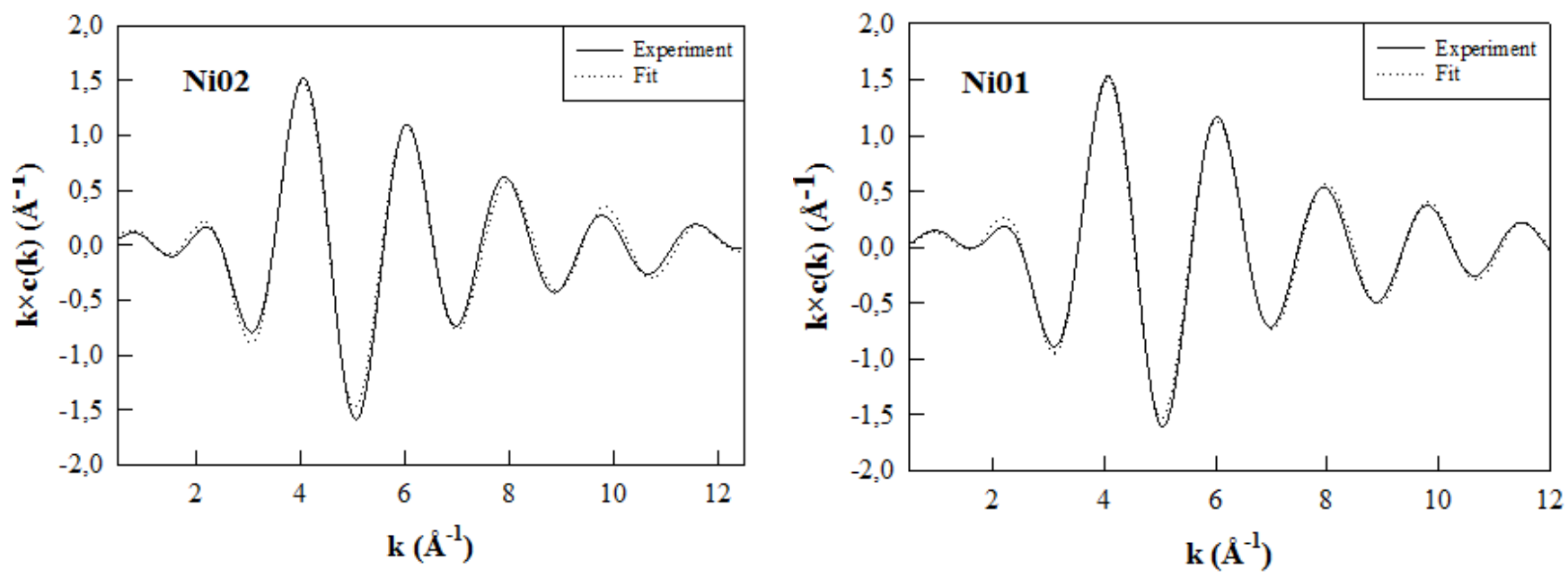

The best simulations of the FF contribution of the NNN peaks obtained for samples Ni01 and Ni02, with the number of $\mathrm{M}$ element fixed to four, are represented in Figure 10 and the structural parameters derived from these simulations are reported in Table 1, together with the parameters obtained for the simulations of NNN shell contributions at the Zn K-edge of samples Zn01 and Zn02 [13]. The mean $\mathrm{Ni}-\mathrm{Ni}$ and $\mathrm{Ni}-\mathrm{Al}$ interatomic distances slightly increase from 3.00 and $3.02 \AA$ respectively in Ni01 to 3.03 and $3.05 \AA$ in Ni02 (Table 1). Ni-Ni and Ni-Al distances in the octahedral sheet are very close and even Ni-Si distances between the elements located in the octahedral and tetrahedral sheets are similar. 
Table 1. Structural parameters derived from $M K$-edge EXAFS analysis of the NN and NNN shells for samples Ni01 and Ni02 (this work), samples Zn01, Zn02, Mg01 and Mg02 (references $[13,52,54])$.

\begin{tabular}{|c|c|c|c|c|c|}
\hline & Sample & Shell & $N$ & $D(\AA)$ & $\sigma^{2}(\AA)$ \\
\hline \multirow{8}{*}{ NN shell } & $\mathrm{Ni01}$ & $\mathrm{Ni}-\mathrm{O}$ & $6.0^{\mathrm{a}}$ & $2.05 \pm 0.02$ & 0.005 \\
\hline & $\mathrm{Ni02}$ & $\mathrm{Ni}-\mathrm{O}$ & $6.0^{\mathrm{a}}$ & $2.05 \pm 0.02$ & 0.005 \\
\hline & Zn01 & $\mathrm{Zn}-\mathrm{O}$ & 5.9 & $2.08 \pm 0.02$ & 0.004 \\
\hline & \multirow{2}{*}{ Zn02 } & $\mathrm{Zn}-\mathrm{O}$ & 5.9 & $2.07 \pm 0.02$ & 0.004 \\
\hline & & Al-O & $6.0^{\mathrm{a}}$ & $1.92 \pm 0.02$ & 0.008 \\
\hline & $\mathrm{Mg} 01$ & $\mathrm{Mg}-\mathrm{O}$ & $6.0^{\mathrm{a}}$ & $2.12 \pm 0.02$ & 0.006 \\
\hline & \multirow{2}{*}{$\mathrm{Mg} 02$} & $\mathrm{Mg}-\mathrm{O}$ & $6.0^{\mathrm{a}}$ & $2.13 \pm 0.02$ & 0.007 \\
\hline & & $\mathrm{Al}-\mathrm{O}$ & $6.0^{\mathrm{a}}$ & $1.93 \pm 0.02$ & 0.006 \\
\hline \multirow{12}{*}{ NNN shell } & \multirow{3}{*}{ Ni01 } & $\mathrm{Ni}-\mathrm{Ni}$ & $1.2^{\mathrm{b}}$ & $3.00 \pm 0.01$ & 0.003 \\
\hline & & $\mathrm{Ni}-\mathrm{Al}$ & $2.8^{b}$ & $3.02 \pm 0.01$ & 0.004 \\
\hline & & $\mathrm{Ni}-\mathrm{Si}$ & $4.0^{\mathrm{a}}$ & $3.20 \pm 0.04$ & 0.002 \\
\hline & \multirow{3}{*}{$\mathrm{Ni02}$} & $\mathrm{Ni}-\mathrm{Ni}$ & $2.1^{\mathrm{b}}$ & $3.03 \pm 0.01$ & 0.004 \\
\hline & & $\mathrm{Ni}-\mathrm{Al}$ & $1.9^{\mathrm{b}}$ & $3.05 \pm 0.01$ & 0.006 \\
\hline & & $\mathrm{Ni}-\mathrm{Si}$ & $4.0^{\mathrm{a}}$ & $3.21 \pm 0.04$ & 0.004 \\
\hline & \multirow{3}{*}{ Zn01 } & $\mathrm{Zn}-\mathrm{Zn}$ & $2.0^{\mathrm{b}}$ & $3.11 \pm 0.04$ & 0.005 \\
\hline & & $\mathrm{Zn}-\mathrm{Al}$ & $2.0^{\mathrm{b}}$ & $2.98 \pm 0.04$ & 0.007 \\
\hline & & $\mathrm{Zn}-\mathrm{Si}$ & $4.0^{\mathrm{a}}$ & $3.17 \pm 0.04$ & 0.005 \\
\hline & \multirow{3}{*}{ Zn02 } & $\mathrm{Zn}-\mathrm{Zn}$ & $2.3^{b}$ & $3.11 \pm 0.04$ & 0.006 \\
\hline & & $\mathrm{Zn}-\mathrm{Al}$ & $1.7^{\mathrm{b}}$ & $2.97 \pm 0.04$ & 0.006 \\
\hline & & $\mathrm{Zn}-\mathrm{Si}$ & $4.0^{\mathrm{a}}$ & $3.25 \pm 0.04$ & 0.005 \\
\hline
\end{tabular}

${ }^{\mathrm{a}}$ fixed parameter, ${ }^{\mathrm{b}}$ Sum of $N_{\mathrm{M}-\mathrm{Al}}$ and $N_{\mathrm{M}-\mathrm{M}}$ fixed to 4.0 .

Figure 10. Best fits performed on the Fourier-filtered NNN shell contribution of samples Ni01 and Ni02 using the parameters and conditions reported in Table 1.
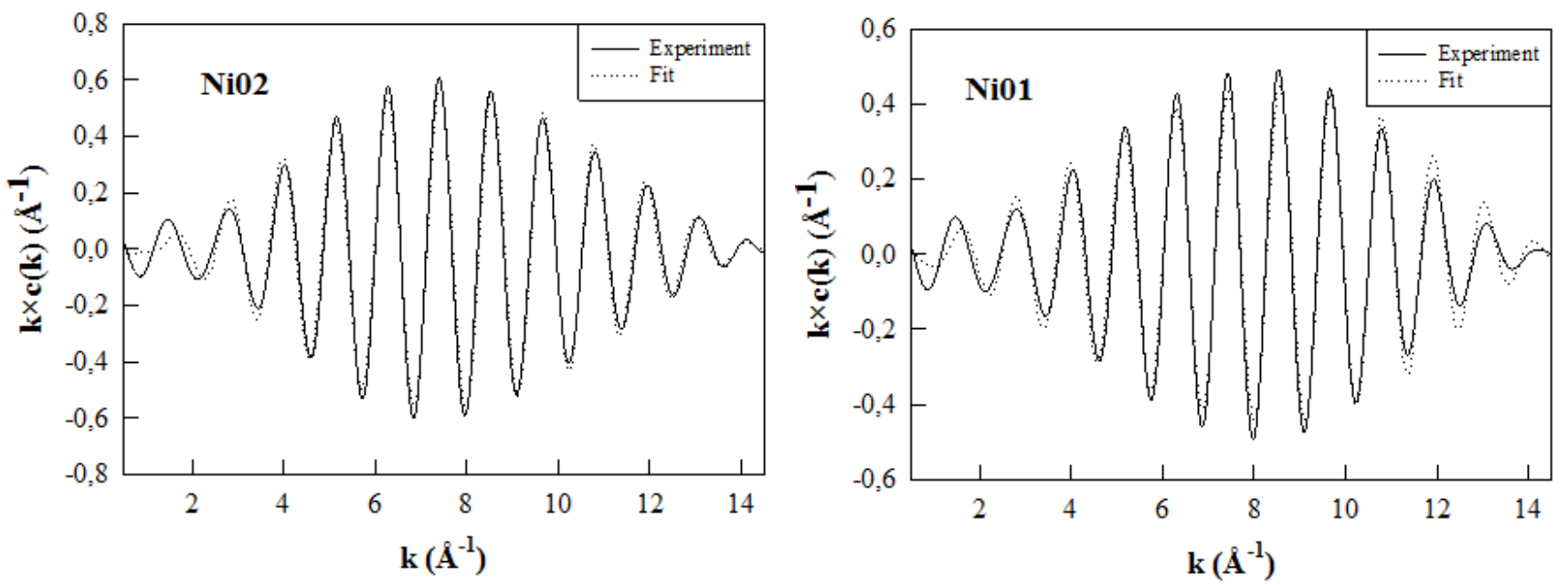

The proportion of Ni nuclei in the NNN shell increases with the Ni content, as one would expect (Table 1). Though these proportions, 1.2 and 2.1 in Ni01 and Ni02 respectively, are much larger than expected for a statistical distribution of the $\mathrm{M}$ elements in the octahedral sheet. The central Ni nucleus should indeed not witness any other Ni nucleus in its NNN shell in the case of Ni01 sample, and it 
should see less than one Ni nucleus in the case of the Ni02 sample, as in the case of Zn-containing phyllosilicates [13]. This is the evidence of the clustering of the M elements in the octahedral sheet of the Ni-Al montmorillonite-like phyllosilicates, containing only $\mathrm{Ni}$ and $\mathrm{Al}$ in this sheet, which confirms the ${ }^{19} \mathrm{~F}$ solid-state NMR observations. However, if there are similarities in the clustering of the $\mathrm{M}$ elements in both $\mathrm{Ni}-\mathrm{Al}$ and $\mathrm{Zn}-\mathrm{Al}$ containing samples, there are slight discrepancies in terms of the proportions of the $\mathrm{M}$ elements surrounding the central $\mathrm{M}$ nucleus, and there are significant differences concerning the values of the M-M distances. In fact, the proportion of $\mathrm{Zn}$ surrounding the central $\mathrm{Zn}$ nucleus seems to be slightly larger, for similar $\mathrm{M}$ elements content, than the proportion of $\mathrm{Ni}$ surrounding the central Ni nucleus (Table 1). This observation would lead to a greater clustering of the $\mathrm{M}$ elements in the case of the $\mathrm{Zn}-\mathrm{Al}$ phyllosilicates, containing only $\mathrm{Zn}$ and $\mathrm{Al}$ in the octahedral sheet. Additionally, the Ni-Ni, Ni-Al and Ni-Si distances in the Ni-Al containing samples are close to the ideal $\mathrm{M}-\mathrm{M}$ distance $[13,55]$. The $\mathrm{Ni}$ environment is less affected by the Ni content than the $\mathrm{Zn}$ environment is by the $\mathrm{Zn}$ content in the $\mathrm{Zn}-\mathrm{Al}$ samples. The $\mathrm{Zn}-\mathrm{Zn}$ distance is indeed longer than the $\mathrm{Zn}-\mathrm{Al}$ distance (Table 1), consequently longer than the ideal M-M distance, and the Zn-Si distance increases with the $\mathrm{Zn}$ content of the samples (Table 1). These observations highlight the existence of distortions in the layer structure of the $\mathrm{Zn}-\mathrm{Al}$ phyllosilicates, which may thus counterbalance the effect of the higher clustering of the elements compared to the Ni-Al phyllosilicates. Additionally, the Ni-Ni distances being significantly shorter than the Zn-Zn ones, also supports the idea of lesser clustering in $\mathrm{Ni}-\mathrm{Al}$ montmorillonites than in Zn-Al montmorillonites. All these considerations explain the improved local order around Ni nuclei, which is sustained by lower Ni-Ni and Ni-Al Debye-Waller factors. As a consequence, the local environment of the $\mathrm{Ni}$ nucleus seems to be more organized than the local environment of the $\mathrm{Zn}$ nucleus in these kinds of montmorillonite-like phyllosilicates.

As a complement to the NNN shell study we would like to highlight that if the best simulations are obtained with a number of four $\mathrm{M}$ elements surrounding the central $\mathrm{Ni}$ atom, simulations using three $\mathrm{M}$ elements were also performed, but with less success (data not shown). Clearly, in the case of a statistical distribution of the $\mathrm{M}$ elements in the octahedral layer of a dioctahedral phyllosilicate, the number of hexagonal sites occupied around a given one is three out of six (Figure 7). However, if sample Ni01 is dioctahedral in nature, sample Ni02 is partially trioctahedral, as observed by XRD (vide supra). Thus, we conducted a first series of fit with three neighbors out of six around the central atom (dioctahedral character). Modifying the number of NNN elements surrounding the central $\mathrm{Ni}$ atom is possible since the FEFF input file used for the theoretical FEFFIT calculations (see experimental section below) contains coordinates of up to six surrounding $\mathrm{M}$ sites forming as many Ni-M pairs (M being Ni or Al). As expected, because of the results for Zn-Al montmorillonites [13], the simulations performed with three $\mathrm{M}$ neighbors did not fit well. Simulations with four neighbors were more successful, as explained above, which supports the existence of a clustering of the octahedral vacancies.

$\mathrm{Al}$ and $\mathrm{Mg} K$-edge EXAFS analysis of synthetic montmorillonites containing $\mathrm{Mg}$ and $\mathrm{Al}$ in their octahedral sheet has revealed that the mean first shell coordination radii of $\mathrm{Al}$ and $\mathrm{Mg}$ are quite different: in fact the bond lengths have been found to be $\mathrm{R}_{\mathrm{Al}-\mathrm{O}}=1.95 \pm 0.03 \AA$ and $\mathrm{R}_{\mathrm{Mg}-\mathrm{O}}=2.11 \pm 0.02 \AA[52,54]$. In the ideal montmorillonite structure, the smaller $\mathrm{Al}^{3+}$ cations (ionic radius: $0.54 \AA)$ are located in $\mathrm{M}_{2}$ sites $\left(\mathrm{R}_{\mathrm{Al}-\mathrm{O}}=1.95 \AA\right.$ ) and the bigger $\mathrm{Mg}^{2+}$ cations (ionic radius: $0.72 \AA)$ are located in $\mathrm{M}_{1}$ sites $\left(\mathrm{R}_{\mathrm{Mg}-\mathrm{O}}=2.15 \AA\right)$. Those values are very close to the Al-O and $\mathrm{Mg}-\mathrm{O}$ 
bond lengths derived from $\mathrm{Al}$ and $\mathrm{Mg} K$-edge EXAFS analysis performed on montmorillonites synthesized in fluoride medium [13,52]. Some of the octahedral sites are empty, in order to ensure a mean charge of two in the whole octahedral sheet.

In the $\mathrm{Ni}-\mathrm{Al}$ montmorillonite, the mean $\mathrm{Ni}-\mathrm{O}$ distance is found to be $2.05 \AA$. If $\mathrm{Ni}^{2+}$ divalent cations (ionic radius: 0.69 ) occupy the $\mathrm{M}_{1}$ sites, their local environment becomes distorted and differs from the ideal montmorillonite structure. The lattice distortion becomes more and more important as with increasing the Ni content. This interpretation is consistent with the increase of $\sigma^{2}$ Debye-Waller factor in the Ni02 sample, with respect to the Ni01 sample (Table 1). Furthermore, the significant increase of the mean $\mathrm{Ni}-\mathrm{Ni}$ and $\mathrm{Ni}-\mathrm{Al}$ interatomic distances, from 3.00 and $3.02 \AA$ respectively in Ni01 to 3.03 and $3.05 \AA$ in Ni02 (Table 1), suggests that more adjoining octahedral sites are filled than in the ideal montmorillonite structure $\left(\mathrm{R}_{\mathrm{M}-\mathrm{M}}=3.00 \AA\right.$ for both $\mathrm{M}_{1}$ and $\mathrm{M}_{2}$ sites $)$. This result is consistent with the observation of Ni-Ni-Ni triads in ${ }^{19} \mathrm{~F}$ NMR together with the lack of Ni-Ni- $\square$ environments. In fact, the octahedral sheet of natural montmorillonites contains transition metal cations either di- or trivalent, like $\mathrm{Ni}$ and $\mathrm{Fe}$, and some vacancies, which ensures a suitable distribution of charges through the sheet. The presence of only Ni divalent transition metal cations in Ni-Al montmorillonite may induce a filling of empty octahedral sites as with increasing the Ni content. When divalent cations become in excess, they fill the empty octahedral sites in some parts of the octahedral sheet, leading to the splitting of the 060 reflection on XRD patterns, which is the fingerprint of di- and tri-octahedral character of the clay structure. Possible higher local charge within the octahedral layer, induced by the metal elements clustering, might be compensated by a lower local charge in the tetrahedral layer, which would be at the origin of the Al for Si substitutions in the tetrahedral layer.

\section{Experimental Section}

\subsection{Synthesis}

The samples presented in this work were hydrothermally synthesized in a fluoride medium using a $120 \mathrm{~cm}^{3}$ PTFE-lined stainless steel autoclave. The hydrogel composition was based on the following ideal montmorillonite-like phyllosilicate half-unit-cell formula: $\mathrm{Na}_{2 x}\left(\mathrm{Al}_{2(1-x)} \mathrm{Ni}_{2 x} \square\right) \mathrm{Si}_{4} \mathrm{O}_{10}(\mathrm{OH})_{2}$, where $x$ equals 0.10 or 0.20 . Reagents were mixed in the following order: deionized water, hydrofluoric acid (HF, 40\%; $\mathrm{BDH}$, diluted to 5\%), $\mathrm{Na}$ (sodium acetate, $\mathrm{CH}_{3} \mathrm{COONa}, 99 \%$; Fluka), Ni (nickel acetate, $\mathrm{Ni}\left(\mathrm{CH}_{3} \mathrm{COO}\right)_{2} 4 \mathrm{H}_{2} \mathrm{O}$, 98\%; Fluka), $\mathrm{Al}$ (pseudo-boehmite, $\mathrm{Al}_{2} \mathrm{O}_{3}, 75 \%-78 \%$, Pural SB1; Condea) and $\mathrm{Si}\left(\mathrm{SiO}_{2}, 99.5 \%\right.$, Aerosil 130; Degussa) sources to form hydrogels with the following composition $1 \cdot \mathrm{SiO}_{2}:(1-2 x) / 4 \cdot \mathrm{Al}_{2} \mathrm{O}_{3}: x / 2 \cdot \mathrm{NiO}: x / 4 \cdot \mathrm{Na}_{2} \mathrm{O}: 0.05 \cdot \mathrm{HF}: 96 \cdot \mathrm{H}_{2} \mathrm{O}$. The amounts of deionized water, hydrofluoric acid and silicon oxide were the same for each synthesis. Hydrogels were matured for $2 \mathrm{~h}$ at room temperature and then autoclaved under autogenous pressure for $72 \mathrm{~h}$ at $493 \mathrm{~K}$. After reaction, autoclaves were quenched to room temperature under a stream of water. The initial and final $\mathrm{pH}$ values were 5.5 (prior to autoclaving) and 3.5-4.0 (end of crystallization) respectively. Final products were thoroughly washed by filtration using deionized water and dried at $333 \mathrm{~K}$ overnight. Samples were then ground to a fine powder and placed under a relative humidity of $P / P_{0}=0.80$, by using a saturated solution of ammonium chloride. Samples were labeled as Ni01 and Ni02 for $x$ equals 0.10 and 0.20 
respectively. Some Ni02 sample was ion-exchanged with hexadecyltrimethylammonium bromide (HDTMABr) (98\%, Avocado) to probe the swelling properties of the sample.

\subsection{Analytical Methods}

\subsubsection{X-Ray Powder Diffraction (XRD)}

The X-ray powder diffraction patterns were recorded on two different diffractometers. The first instrument was a PANalytical X'pert Pro diffractometer with fixed slits using $\mathrm{Cu}-\mathrm{K}_{\alpha}$ radiation $(\lambda=1.5418 \AA)$ and $\theta-2 \theta$ configuration. Before analyses, powder samples were finely ground and pressed in a stainless steel sample holder. Data were recorded from $3^{\circ}$ to $70^{\circ} 2 \theta$ with a step size of $0.02^{\circ}$ point and a rate of $0.6^{\circ} \mathrm{min}^{-1}$ at a voltage of $35 \mathrm{kV}$ and a current intensity of $55 \mathrm{~mA}$. The second diffractometer employing $\mathrm{Cr}-\mathrm{K}_{\alpha}$ radiation with fixed divergence slits, Philips PW1100, was used to record more precisely the d-spacing $\left(d_{001}\right)$ of the Ni02 sample intercalated with hexadecyltrimethyl ammonium cations (HDTMA). Patterns were recorded from 1 to $35^{\circ} 2 \theta$ with a step size of $0.02^{\circ} /$ point and a rate of $0.2^{\circ} \mathrm{min}^{-1}$ at a voltage of $35 \mathrm{kV}$ and a current intensity of $50 \mathrm{~mA}$. In both cases diffractograms were performed on powders which were only pressed on sample holders. Information about the phase and $d_{001}$ spacing was obtained with the APD 1700 software (Philips).

\subsubsection{Chemical Analysis}

A part of each sample was Na-saturated to insure that only $\mathrm{Na}^{+}$cations balanced the layer charge. Elemental analysis of the samples was performed by the Service Central d'Analyse of the Centre National de la Recherche Scientifique (Vernaison, France) for the following elements: Ni, Al, Si, and F. After mineralization, metal elements and fluorine contents were analyzed using inductively coupled plasma mass spectrometry.

\subsubsection{Scanning Electron Microscopy (SEM)}

Starting materials were examined by SEM with a Philips XL30 microscope in order to determine their morphology. Prior to analysis, a few milligrams of powder was dispersed in ethanol and a few droplets of the suspension were left to evaporate on a holder covered with graphite. Samples were then gold-plated by sputtering under vacuum.

\subsubsection{Transmission Electron Microscopy (TEM)}

Samples were examined by TEM using a Jeol JEM 1230 microscope equipped with a $\mathrm{LaB}_{6}$ filament and working at an excitation voltage of $80 \mathrm{kV}$. Prior to analysis, a few milligrams of sample was dispersed in methanol and a few droplets of the suspension were left to evaporate on a tiny nickel grid covered with a Formvar film.

\subsubsection{Thermogravimetric and Differential Thermal Analysis (TGA-DTA)}

Measurements were carried out from room temperature to $1273 \mathrm{~K}$ at a heating rate of $5 \mathrm{~K} \mathrm{~min}^{-1}$ under a mixture of nitrogen and oxygen gas ( 1 and 0.5 bars, respectively) using a Setaram Labsys 
apparatus. Typically about 30 to $45 \mathrm{mg}$ of powder previously equilibrated at a controlled humidity of $P / P_{0}=0.80$ during $48 \mathrm{~h}$ was introduced in an alumina crucible to perform the measurement.

\subsubsection{Nitrogen Adsorption-Desorption Manometry Experiments (BET)}

Nitrogen adsorption-desorption experiments were performed at the temperature of liquid nitrogen (77 K) using a Coulter Omnisorp 100 gas analyzer. The specific surface area was deduced from the most linear portion of the BET (Brunauer Emmett and Teller) plot $\left(P / P_{0}=0.006-0.10\right)$. The micropore volume was determined using the t-plot method. Samples were pretreated at $573 \mathrm{~K}$ under vacuum over $4 \mathrm{~h}$ prior to the analysis.

\subsubsection{Magic Angle Spinning Nuclear Magnetic Resonance (MAS-NMR)}

The ${ }^{29}$ Si MAS-NMR spectra were recorded using a Bruker ${ }^{\circledR}$ MSL-300 spectrometer at $59.63 \mathrm{MHz}$, using a $7 \mathrm{~mm}$ MAS probe, $2 \mu$ s excitation pulses $(\pi / 2$ pulse width of $4 \mu \mathrm{s})$ and $95 \mathrm{~s}$ recycle time. Spectra were recorded by accumulating 600 scans at a spinning rate of $4 \mathrm{kHz}$. Chemical shifts of $\mathrm{Si}$ were referenced to tetramethylsilane (TMS) using a secondary standard of trimethylsilylester of cubic octameric silicate (Q8M8) at $-109.7 \mathrm{ppm}$ (the more shielded signal). The ${ }^{27}$ Al MAS-NMR spectra were recorded on a Bruker ${ }^{\circledR}$ DSX-400 at $104.27 \mathrm{MHz}$, using a $4 \mathrm{~mm}$ MAS probe, $0.7 \mu$ s excitation pulses $(\pi / 2$ pulse width of $9 \mu$ s for an aqueous solution) and $1 \mathrm{~s}$ recycle time. Spectra were recorded by accumulating 1200 scans at a spinning rate of $12 \mathrm{kHz}$. Chemical shifts of $\mathrm{Al}$ were referenced to a $1 \mathrm{M}$ $\mathrm{Al}\left(\mathrm{NO}_{3}\right)_{3}$ aqueous solution with a chemical shift of $0 \mathrm{ppm}$. The ${ }^{19} \mathrm{~F}$ MAS-NMR spectra were obtained on the DSX-400 spectrometer at $379.23 \mathrm{MHz}$, using the $4 \mathrm{~mm}$ MAS probe, with a Hahn echo pulse sequence ( $\pi / 2$ pulse $-\tau-\pi$ pulse $-\tau-$ acquisition), $25-30 \mathrm{kHz}$ spinning speed, $\pi / 2$ pulse width of $4 \mu$ s and $10 \mathrm{~s}$ recycle time. The value of $\tau$ was synchronized to a rotation period of the spinner. Spectra were recorded by accumulating 612 scans and the chemical shifts of $F$ were referenced to octadecasil with a chemical shift of 0 ppm. After their collection, free induction decay (FID) signals were treated following a standard procedure using the WIN-NMR software (Bruker ${ }^{\circledR}$, Bruker Biospin GmbH: Rheinstetten, Germany, 2001). The FID signals were smoothed in order to reduce the background noise and the base-line was also corrected if necessary. The ${ }^{29} \mathrm{Si}$ MAS-NMR spectra were simulated with the WINFIT-2002 software using standard procedure [56].

\subsubsection{Ni $K$-Edge Extended X-Ray Absorption Fine Structure (Ni $K$-EXAFS)}

The X-ray absorption experiments were performed at the Laboratoire pour l'Utilisation du Rayonnement Electromagnétique (LURE, Orsay, France). The Ni01 and Ni02 samples were mixed with cellulose ( $0.131 \mathrm{~g}$ of $\mathrm{Ni01}$ and $0.77 \mathrm{~g}$ of Ni02 with 0.012 and $0.050 \mathrm{~g}$ of cellulose respectively) and pressed $(1 \mathrm{~T})$ in the form of pellets (less than $1 \mathrm{~mm}$ thick), which were maintained between two Kapton windows. Measurements were performed on the D21 beam line of the DCI storage ring. The X-rays were monochromatized by an $\mathrm{Si}(311)$ two-crystal spectrometer. The X-ray absorption spectra were recorded at the $\mathrm{Ni} K$-edge $(8333 \mathrm{eV})$ from 8200 to $9300 \mathrm{eV}\left(1 \mathrm{eV}\right.$ step; $2 \mathrm{~s}^{-1}$ per point $)$ in transmission mode at $20 \mathrm{~K}$. 
The raw data were processed following standard procedure by using the ATHENA routine (Bruce Ravel, The University of Chicago) [57], which works under the IFEFFIT interactive program for X-ray Absorption Spectroscopy (XAS) analysis (Matthew Newville, The University of Chicago, Chicago, IL, USA) [58]. First the pre-edge and post-edge backgrounds were removed from the raw data and the obtained absorption spectra normalized. The $\mathrm{E}_{0}$ origin of the kinetic energies of the photoelectron was taken at $8339 \mathrm{eV}$ for all samples. After conversion to $\mathrm{k}$-space ( $\mathrm{k}$ being the wave vector of the photoelectron scattering on the neighboring atoms), the spectra were $\mathrm{k} 1$-weighted and Fourier-transformed (FT) between 2.0 and $13.8 \AA^{-1}$ using a Kaiser-Bessel apodization window.

The nearest neighbours (NN) and next-nearest neighbours (NNN) peaks in the Fourier transforms (FT) were assigned to the oxygen and metal backscatterers. The FT and Fourier-filtered (FF) contributions of oxygen $\mathrm{NN}$ and metallic $\mathrm{NNN}$ were simulated using the ARTEMIS routine [57] in order to derive the structural parameters: the interatomic distances $R$, coordination numbers $N$ and Debye-Waller (DW) parameters $\sigma$. Montmorillonite structure possess two octahedral sites $\left(\mathrm{M}_{1}\right.$ and $\left.\mathrm{M}_{2}\right)$ which are occupied by metallic cations, the mean M-O first distances being 2.15 and $1.91 \AA$ for $\mathrm{M}_{1}$ and $\mathrm{M}_{2}$ sites, respectively [54]. Thus, the model was carried out by running FEFF-6 [59] with an input file constituted by the coordinates of the first $\mathrm{O}$ shell atoms surrounding an $\mathrm{M}_{2}$ octahedral site (arbitrarily chosen as the central atom), and then of the $M_{1}$ and $M_{2}$ octahedral sites and of the $\mathrm{Si}(\mathrm{Al})$ atoms present in the tetrahedral sheet for the second atomic shell. A Ni occupation level introduced in the ab-initio calculations was allowed to vary as other fitting parameters, and finely adjusted step by step.

\section{Conclusions}

In this work, synthesis of Ni-Al 2:1 phyllosilicates, containing only $\mathrm{Ni}$ and $\mathrm{Al}$ in their octahedral sheet, was performed under hydrothermal conditions using the fluoride medium route. The obtained materials are pale green powders exhibiting a layer structure and a sand rose morphology, as shown by TEM and SEM respectively, which is characteristic of montmorillonite minerals. The XRD and thermal analysis data exhibit characteristic features of clay minerals and more specifically to montmorillonite-like phyllosilicates. XRD also show that the sample containing the highest amount of $\mathrm{Ni}(\mathrm{Ni} 02)$ possesses a partial trioctahedral character. ${ }^{29} \mathrm{Si}$ and ${ }^{27} \mathrm{Al}$ NMR show the existence of $\mathrm{Al}$ for Si substituted in the tetrahedral sheet. ${ }^{29} \mathrm{Si}$ NMR demonstrates the presence of amorphous silica in the samples, especially in sample Ni02. Chemical analysis confirms that the Ni content is somehow doubled from sample $\mathrm{Ni01}$ to Ni02, as expected, but no chemical formula could be determined because of the presence of an amorphous silica phase. The samples have relatively large specific surface areas $\left(>100 \mathrm{~m}^{2} \mathrm{~g}^{-1}\right)$, though a non-negligible proportion of it comes from the amorphous phase. ${ }^{19} \mathrm{~F}$ NMR highlights a clustering of the metal elements and of the vacancies in the octahedral sheet of the samples. A Ni $K$-edge EXAFS study enabled the attainment in both samples of the Ni-M distances and the proportion of $\mathrm{M}$ elements $(\mathrm{Ni}$ or $\mathrm{Al}$ ) surrounding the $\mathrm{Ni}$ nuclei. The analysis of these EXAFS data confirms unambiguously the clustering of both the $\mathrm{M}$ elements and the vacancies in the octahedral sheet, as observed previously in $\mathrm{Zn}-\mathrm{Al}$ or $\mathrm{Mg}$-Al montmorillonite-like phyllosilicates, containing only $\mathrm{Zn}$ and $\mathrm{Al}$ or $\mathrm{Mg}$ and $\mathrm{Al}$ in the octahedral sheet. The comparison of $\mathrm{Ni}$ and $\mathrm{Zn} K$-edges results highlights a more important clustering of the M elements in the $\mathrm{Zn}-\mathrm{Al}$ phyllosilicates than in the $\mathrm{Ni}-\mathrm{Al}$ 
containing ones. Additionally, the Ni-Al phyllosilicates exhibit a higher local ordering around Ni. In natural montmorillonites, the distribution of di- and trivalent transition metal elements ensures the charge equilibrium over the whole octahedral sheet and allows a certain stability of the framework. Even if local defects lead to a trioctahedral character, the whole clay structure is preserved. Unlike natural montmorillonites, the synthetic montmorillonites were prepared from one sort of metallic divalent element, $\mathrm{Mg}^{2+}, \mathrm{Zn}^{2+}$, or $\mathrm{Ni}^{2+}$ in the present study. Their clustering in some part of the sheet results from the local loss of charge balance and leads not only to a trioctahedral character but also to severe distortions and instability of the structure when their content exceeds $c a$. 20\%, as was observed in our previous study [13] and confirmed in the present work. Such charge and/or structural distortion defects may be compensated by Al for Si substitutions in the tetrahedral layer. The first goal of our study, the synthesis of montmorillonite-like Ni-Al phyllosilicates, containing solely $\mathrm{Ni}$ and $\mathrm{Al}$ in their octahedral sheet, was successfully achieved. This unprecedented success opens interesting perspectives on the synthesis of clay-like compounds containing various other transition metals in their structure. These new synthetic materials are presently being evaluated for their catalytic properties.

\section{References}

1. Vaccari, A. Clays and catalysis: A promising future. Appl. Clay Sci. 1999, 14, 161-198.

2. Carretero, M.I.; Lagaly, G. Clays and health: An introduction. Appl. Clay Sci. 2007, 36, 1-3.

3. Zhang, D.; Zhou, C.-H.; Lin, C.-X.; Tong, D.-S.; Yu, W.-H. Synthesis of clay minerals. Appl. Clay Sci. 2010, 50, 1-11.

4. Konta, J. Clay and man: Clay raw materials in the service of man. Appl. Clay Sci. 1995, 10, 275-335.

5. Murray, H.H. Traditional and new applications for kaolin, smectite, and palygorskite: A general overview. Appl. Clay Sci. 2000, 17, 207-221.

6. Ding, Z.; Kloprogge, J.T.; Frost, R.L.; Lu, G.Q.; Zhu, H.Y. Porous clays and pillared clays-based catalysts. Part 2: A review of the catalytic and molecular sieve applications. J. Porous Mater. 2001, 8, 273-293.

7. Carretero, M.I. Clay minerals and their beneficial effects upon human health. A review. Appl. Clay Sci. 2002, 21, 155-163.

8. Babel, S.; Kurniawan, T.A. Low-cost adsorbents for heavy metals uptake from contaminated water: A review. J. Hazard. Mater. 2003, 97, 219-243.

9. Choy, J.-H.; Choi, S.-J.; Oh, J.-M.; Park, T. Clay minerals and layered double hydroxides for novel biological applications. Appl. Clay Sci. 2007, 36, 122-132.

10. Martin, R.T.; Bailey, S.W.; Eberl, D.D.; Fanning, D.S.; Guggenheim, S.; Kodama, H.; Pevear, D.R.; Srodon, J.; Wicks, F.J. Report of the clay minerals society nomenclature committee; revised classification of clay materials. Clays Clay Miner. 1991, 39, 333-335.

11. Caillère, S.; Hénin, S.; Rautureau, M. Minéralogie des argiles, Tome 1: Structure et propriétés physico-chimiques, 2nd ed.; Masson: Paris, France, 1982.

12. Zhou, C.H. An overview on strategies towards clay-based designer catalysts for green and sustainable catalysis. Appl. Clay Sci. 2011, 53, 87-96. 
13. Reinholdt, M.; Miehé-Brendlé, J.; Delmotte, L.; Tuilier, M.-H.; Le Dred, R.; Cortès, R.; Flank, A.-M. Fluorine route synthesis of montmorillonites containing $\mathrm{Mg}$ or $\mathrm{Zn}$ and characterization by XRD, thermal analysis, MAS NMR, and EXAFS spectroscopy. Eur. J. Inor. Chem. 2001, 11, 2831-2841.

14. Reinholdt, M.; Miehé-Brendlé, J.; Delmotte, L.; Tuilier, M.-H.; Le Dred, R. Synthesis and characterization of montmorillonite-type phyllosilicates in a fluoride medium. Clay Miner. 2005, 40, 177-189.

15. Lantenois, S.; Champallier, R.; Bény, J.-M.; Muller, F. Hydrothermal synthesis and characterization of dioctahedral smectites: A montmorillonites series. Appl. Clay Sci. 2008, 38, $165-178$.

16. Le Forestier, L.; Muller, F.; Villieras, F.; Pelletier, M. Textural and hydration properties of a synthetic montmorillonite compared with a natural Na-exchanged clay analogue Appl. Clay Sci. 2010, 48, 18-25.

17. Otsubo, Y.; Kato, C. Hydrothermal synthesis of montmorillonite-type silicates III. J. Chem. Soc. Jpn. 1954, 75, 456-459.

18. Nagase, T.; Iwasaki, T.; Ebina, T.; Hayashi, H.; Onodera, Y.; Chandra-Dutta, N. Hydrothermal synthesis of Fe-montmorillonite in Si-Fe-Mg system. Chem. Lett. 1999, 4, 303-304.

19. Centi, G.; Perathoner, S. Catalysis by layered materials: A review. Microporous Mesoporous Mater. 2008, 107, 3-15.

20. Trujillano, R.; Vicente, M.A.; Rives, V.; Korili, S.A.; Gil, A.; Ciuffi, K.J.; Nassar, E.J. Preparation, alumina-pillaring and oxidation catalytic performances of synthetic Ni-saponite. Microporous Mesoporous Mater. 2009, 117, 309-316.

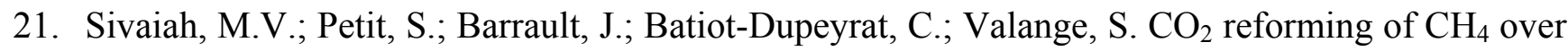
Ni-containing phyllosilicates as catalyst precursors. Catal. Today 2010, 157, 397-403.

22. Sivaiah, M.V.; Petit, S.; Beaufort, M.F.; Eyidi, D.; Barrault, J.; Batiot-Dupeyrat, C.; Valange, S. Nickel based catalysts derived from hydrothermally synthesized 1:1 and 2:1 phyllosilicates as precursors for carbon dioxide reforming of methane. Microporous Mesoporous Mater. 2011, 140, 69-80.

23. Watanabe, T.; Sato, T. Expansion characteristics of montmorillonite and saponite under various relative humidity conditions. Clay Sci. 1988, 7, 129-138.

24. Yamada, H.; Nakazawa, H.; Hashizume, H.; Shimomura, S.; Watanabe, T. Hydration behavior of Na-smectite crystals synthesized at high pressure and high temperature. Clays Clay Miner. 1994, $42,77-80$.

25. Boeck, E.S.; Coveney, P.V.; Skipper, N.T. Monte Carlo molecular modeling studies of hydrated Li-, Na- and K-smectites: Understanding the role of potassium as a clay swelling inhibitor. J. Am. Chem. Soc. 1995, 117, 12608-12617.

26. Bonczek, J.L.; Harris, W.G.; Nkedi-Kizza, P. Monolayer to bilayer transitional arrangements of hexadecyltrimethylammonium cations on Na-Montmorillonite. Clays Clay Miner. 2002, 50, 11-17.

27. He, H.; Frost, R.L.; Bostrom, T.; Yuan, P.; Duong, L.; Yang, D.; Xi, Y.; Kloprogge, J.T. Changes in the morphology of organoclays with $\mathrm{HDTMA}^{+}$surfactant loading. Appl. Clay Sci. 2006, 31, 262-271. 
28. Lapides, I.; Borosiver, M.; Yariv, S. Thermal analysis of hexadecyltrimethylammonium-montmorillonites Part 2. Thermo-XRD-spectroscopy-analysis. $J$. Therm. Anal. Calorim. 2011, 105, 39-51.

29. Lapides, I.; Borosiver, M.; Yariv, S. Thermal analysis of hexadecyltrimethylammonium-montmorillonites Part 1. Thermogravimetry, carbon and hydrogen analysis and thermo-IR spectroscopy analysis. J. Therm. Anal. Calorim. 2011, 105, 921-929.

30. Ma, K.; Pierre, A.C. Colloidal behaviour of montmorillonite in the presence of $\mathrm{Fe}^{3+}$ ions. Colloid Surf. A 1999, 155, 359-372.

31. Cravero, F.; Keith, K.S.; Murray, H.H.; Toth, T. A white bentonite from San Juan Province, Argentina-Geology and potential industrial applications. Appl. Clay Sci. 2000, 16, 31-43.

32. Christidis, G.E. Formation and growth of smectites in bentonites: A case study from Kimolos Island, Aegean, Greece. Clays Clay Miner. 2001, 49, 204-215.

33. B. Bauluz, B.; Peacor, D.R.; Ylagan, R.F. Transmission electron microscopy study of smectite illitization during hydrothermal alteration of a rhyolitic Hyaloclastite from Ponza, Italy. Clays Clay Miner. 2002, 50, 157-173.

34. Cuadros, J.; Delgado, A.; Cardenete, A.; Reyes, E.; Linares, J. Kaolinite/montmorillonite resembles beidellite. Clays Clay Miner. 1994, 42, 643-651.

35. Drits, V.A.; Lindgreen, H.; Salyn, A.L.; Ylagan, R.; McCarty, D.K. Semiquantitative determination of trans-vacant and cis-vacant 2:1 layers in illites and illite-smectites by thermal analysis and X-ray diffraction. Am. Miner. 1998, 83, 1188-1198.

36. Emmerich, K.; Madsen, F.T.; Kahr, G. Dehydroxylation behavior of heat-treated and steam-treated homoionic cis-vacant montmorillonites. Clays Clay Miner. 1999, 47, 591-604.

37. Frost, R.L.; Ruan, H.; Kloprogge, J.T.; Gates, W.P. Dehydration and dehydroxylation of nontronites and ferruginous smectite. Thermochim. Acta 2000, 346, 63-72.

38. Dogan, A.U.; Dogan, M.; Onal, M.; Sarikaya, Y.; Aburub, A.; Wurster, D.E. Baseline studies of the clay minerals society source clays: Specific surface area by the Brunauer Emmett Teller (BET) method. Clays Clay Miner. 2006, 54, 62-66.

39. Salles, F.; Douillard, J.-M.; Denoyel, R.; Bildstein, O.; Jullien, M.; Beurroies, I.; van Damme, H. Hydration sequence of swelling clays: Evolutions of specific surface area and hydration energy.

J. Coll. Interface Sci. 2009, 333, 510-522.

40. Sivaiah, M.V.; Petit, S.; Brendlé, J.; Patrier, P. Rapid synthesis of aluminium polycations by microwave assisted hydrolysis of aluminium via decomposition of urea and preparation of Al-pillared montmorillonite. Appl. Clay Sci. 2010, 48, 138-145.

41. Gautier, M.; Muller, F.; Le Forestier, L.; Beny, J.-M.; Guegan, R. $\mathrm{NH}_{4}$-smectite: Characterization, hydration properties and hydro mechanical behavior. Appl. Clay Sci. 2010, 49, 247-254.

42. Gougeon, R.D.; Soulard, M.; Reinholdt, M; Miehé-Brendlé, J.; Chézeau, J.-M.; Le Dred, R.; Marchal, R.; Jeandet, P. Polypeptide adsorption on a synthetic montmorillonite: A combined solid-state NMR spectroscopy, X-ray diffraction, thermal analysis and $\mathrm{N}_{2}$ adsorption study. Eur. J. Inor. Chem. 2003, 7, 1366-1372.

43. Marty, N.C.M.; Cama, J.; Sato, T.; Chino, D.; Villiéras, F.; Razafitianamaharavo, A.; Brendlé, J.; Giffaut, E.; Soler, J.M.; Gaucher, E.C.; et al. Dissolution kinetics of synthetic Na-smectite. An integrated experimental approach. Geochim. Cosmochim. Acta 2011, 75, 5849-5864. 
44. Sanz, J.; Serratosa, J.M. ${ }^{29} \mathrm{Si}$ and ${ }^{27} \mathrm{Al}$ high-resolution MAS-NMR spectra of phyllosilicates. J. Am. Chem. Soc. 1984, 106, 4790-4793.

45. Janes, N.; Oldfield, E. Prediction of silicon-29 nuclear magnetic resonance chemical shifts using a group electronegativity approach: Applications to silicate and aluminosilicate structures. J. Am. Chem. Soc. 1985, 107, 6769-6775.

46. Weiss, C.A.; Altaner, S.P.; Kirkpatrick, R.J. High-resolution silicon-29 spectroscopy of 2:1 layer silicates: Corellations among chemical shift, structural distortions and chemical variations. Am. Miner. 1987, 72, 935-942.

47. Gates, W.P.; Komadel, P.; Madejová, J.; Bujdak, J.; Stucki, J.W.; Kirkpatrick, R.J. Electronic and structural properties of reduced-charge Montmorillonites. Appl. Clay Sci. 2000, 16, 257-271.

48. Goodman, B.A.; Stucki, J.W. The use of nuclear magnetic resonance (NMR) for the determination of tetrahedral aluminium in montmorillonite. Clay Miner. 1984, 19, 663-667.

49. Drachman, S.R.; Roch, G.E.; Smith, M.E. Solid state NMR characterization of the thermal transformation of Fuller's Earth. Solid State Nucl. Magn. 1997, 9, 257-267.

50. Huve, L. Synthèse de Phyllosilicates en milieu acide et fluoré et leur Caractérisation. PhD Thesis, Université de Haute Alsace, Mulhouse, France, 1992.

51. Huve, L.; Delmotte, L.; Martin, P.; Le Dred, R.; Baron, J.; Saehr, D. ${ }^{19}$ F MAS-NMR study of structural fluorine in some natural and synthetic 2:1 layer silicates. Clays Clay Miner. 1992, 40, 186-191.

52. Reinholdt, M. Synthèse en milieu fluoré et caractérisation de Phyllosilicates de type Montmorillonite. Etude Structurale par Spectroscopies d'Absorption des Rayons X et de Résonance Magnétique Nucléaire. PhD Thesis, Université de Haute Alsace, Mulhouse, France, December 2001.

53. Miehé-Brendlé, J.; Tuilier, M.-H.; Marichal, C.; Gallego, J.-C.; Reinholdt, M. Mg environments in the octahedral sheet of 2:1 talc-like hybrid phyllosilicates: A comparative XAFS study. Eur. J. Inor. Chem. 2010, 35, 5587-5591.

54. Reinholdt, M.; Miehé-Brendlé, J.; Delmotte, L.; Tuilier, M.-H.; Le Dred, R. Si-Al-Mg and Si-Al-Zn Montmorillonite: Synthesis and Characterization by EXAFS and Quantitative ${ }^{27} \mathrm{Al}$ MAS-NMR. In Proceedings of the 12th International Clay Conference, Bahía Blanca, Argentina, July 22-28, 2001; Domínguez, E.A., Mas, G.R., Cravero, F., Eds.; Elsevier: Amsterdam, The Netherlands, 2003.

55. Tsipursky, S.I.; Drits, V.A. The distribution of octahedral cations in the 2:1 layers of dioctahedral smectites studied by oblique-texture electron diffraction. Clay Miner. 1984, 19, 177-193.

56. Massiot, D.; Favon, F.; Capron, M.; King, I.; Le Calvé, S.; Alonso, B.; Durand, J.-O.; Bujoli, B.; Gan, Z.; Hoatson, G. Modelling one- and two-dimensional solid-state NMR spectra. Magn. Reson. Chem. 2002, 40, 70-76.

57. Ravel, B.; Newville, M. ATHENA, ARTEMIS, HEPHAESTUS: Data analysis for X-ray absorption spectroscopy using IFEFFIT. J. Synchrotron Rad. 2005, 12, 537-541.

58. Newville, M. IFEFFIT: Interactive XAFS analysis and FEFF fitting. J. Synchrotron Rad. 2001, 8, $322-324$. 
59. Zabinsky, S.I.; Rehr, J.J.; Ankudinov, A.; Albers, R.C.; Eller, M.J. Multiple-scattering calculations of X-ray-absorption spectra. Phys. Rev. B 1995, 52, 2995-3009.

(C) 2013 by the authors; licensee MDPI, Basel, Switzerland. This article is an open access article distributed under the terms and conditions of the Creative Commons Attribution license (http://creativecommons.org/licenses/by/3.0/). 